\title{
Comparative Analysis of Fuzzy Logic and PI Controller Based Electronic Load Controller for Self-Excited Induction Generator
}

\author{
Eshani Mishra and Sachin Tiwari \\ Department of Electrical and Electronics Engineering, Oriental Institute of Science and Technology, Bhopal, India \\ Correspondence should be addressed to Eshani Mishra; eshani39@gmail.com
}

Received 10 August 2016; Revised 20 October 2016; Accepted 11 June 2017; Published 6 August 2017

Academic Editor: Pascal Venet

Copyright (C) 2017 Eshani Mishra and Sachin Tiwari. This is an open access article distributed under the Creative Commons Attribution License, which permits unrestricted use, distribution, and reproduction in any medium, provided the original work is properly cited.

\begin{abstract}
Rural areas suffer from limited grid connectivity. Small hydroplants can provide electricity at a cheap cost with low environmental impact in these regions. Self-excited induction generators are widely used in hydroplants since they operate on a standalone basis because of the connection of capacitor bank that provides reactive power at no load. However, SEIGs suffer from poor voltage and frequency regulation. Thus, an electronic load controller (ELC) is connected across SEIG to regulate voltage and frequency. Generally, the control scheme for an ELC circuit is based on the conventional proportional integral control, which is easy to implement and performs well under linear load conditions. However, PI controllers handle nonlinearity poorly. This paper presents a fuzzy logic control (FLC) based control scheme for ELC in a constant power generation system (SEIG). The control scheme is designed and simulated in MATLAB under both linear and nonlinear load conditions. A comparison of both the controllers is conducted which highlights the superiority of the fuzzy logic control scheme.
\end{abstract}

\section{Introduction}

The growing focus towards sustainable and efficient power generation has led to development of alternative sources like renewable energy. Hydropower plants are proving to be a viable source for producing electricity in isolated areas. Small hydropower generation system is an efficient option in these isolated areas because of availability of abundant resources and its low environmental impact. Self-excited induction generator (SEIG) is a favorable option for generation of electricity in small hydropower plants in isolated areas with limited grid connectivity. SEIGs are more efficient than the conventional synchronous generators because they are rugged, possess brushless construction, are cheap, require little maintenance, do not require DC excitation, and so forth [1]. However, major disadvantage of SEIG is its inability to maintain voltage and frequency at constant levels [2]. Much research has been done to develop methods to control voltage and frequency in constant power and variable speed and power applications [3-7]. In a hydropower station which is a constant power source, an electronic load controller is connected across the SEIG for its voltage and frequency regulation.
Several approaches have been carried out for ELC and its control schemes. Most of the control schemes are based on carrier-less or hysteresis control using proportional integral (PI) or Proportional Integral Derivative (PID) controls. PI based controllers are simple to implement and less complex [8] but suffer from several drawbacks. They cannot handle nonlinearity in the system and require accurate mathematical models to function. These drawbacks are overcome by fuzzy logic based ELC for the SEIG system. Fuzzy logic controller (FLC) is a viable choice when accurate mathematical calculations are impossible and load conditions are nonlinear. This paper presents a control scheme based on FLC method which implements hysteresis current control method for Pulse Width Modulation (PWM) generation scheme for the pulses given to the Current-Controlled Voltage Source Inverter (CC-VSI). The proposed fuzzy logic based ELC is compared with the conventional PI based controller for SEIG system under linear and nonlinear load conditions. The DC link voltage of both the systems is analyzed and the results highlight that the fuzzy logic controller performs better than the proportional integral controller. 


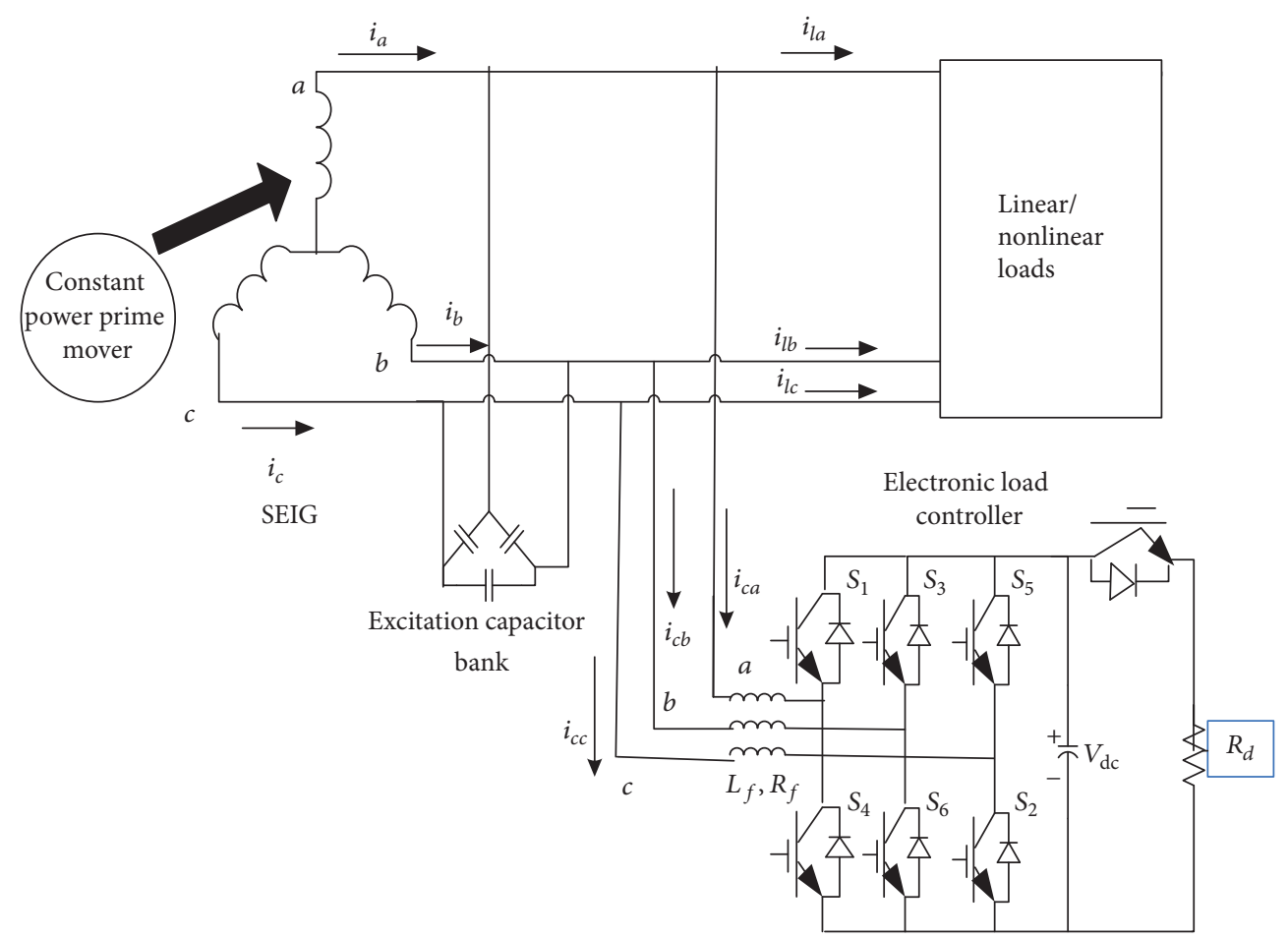

FIgURE 1: Schematic diagram of a standalone self-excited induction generator [9].

\section{System Configuration}

The electronic load controller is designed for a self-excited squirrel cage induction generator with a delta connected fixed capacitor bank across its generator terminal. Figure 1 depicts the schematic diagram of the constant power SEIG connected to ELC system. The ELC comprises three-legged CC-VSI with an IGBT based chopper switch and a series resistor known as the dump load. The capacitor bank is essential for providing the no load excitation to the SEIG [9]. The designing of the chopper switch and dump load and its parameters are important for smooth and uninterrupted operation of ELC. The controller is connected at the point of common coupling (PCC) through the filter circuit. A suitable capacitor is connected across the output terminal which smoothens out the fluctuations in the inverter output voltage. An IGBT is used as a chopper switch whose gate driver circuit has been developed based on fuzzy logic method that turns on the chopper switch when the load on the generator is less than the rated value. The gate pulses for the CC-VSI are controlled using the hysteresis current controller. The hysteresis control is superior to others as it responds rapidly to loads and line transients and is also linear in nature. The ELC persistently senses and regulates the generated frequency and voltage. It compensates for variation in the main load by automatically varying the amount of active power dissipated in the series dump load and reactive power requirement through the DC link capacitor thus providing active and reactive power compensation. Both the proportional integral controller and the fuzzy logic controller based ELCs are modeled and simulated in MATLAB using Simulink and their performance is demonstrated under various linear and nonlinear load conditions $[10,11]$.

\section{Control Schemes}

3.1. Proportional Integral (PI) Controller. The proportional integral is a special case of the typical controller family known as Proportional Integral Derivative (PID) controller. Figure 2 is the basic block diagram explaining the control algorithm for proportional integral control based SEIG system, respectively.

The different steps in the PI controller are modeled as follows [6].

The AC voltage error $V_{\mathrm{er}}$ at the $n$th sampling instant is

$$
V_{\mathrm{er}(n)}=V_{\mathrm{tmref}(n)}-V_{\mathrm{tm}(n)},
$$

where $V_{\operatorname{tmref}(n)}$ is the amplitude of reference AC terminal voltage and $V_{\operatorname{tm}(n)}$ is the amplitude of the sensed three-phase AC voltage at the generator terminal at the $n$th sampling instant.

The output of the PI controller $\left(I_{\mathrm{smq}(n)}\right)$ required to maintain constant $\mathrm{AC}$ terminal voltage at the $n$th sampling instant is computed as

$$
I_{\mathrm{smq}(n)}=I_{\mathrm{smq}(n-1)}+K_{\mathrm{pv}}\left\{V_{\mathrm{er}(n)}-V_{\mathrm{er}(n-1)}\right\}+K_{\mathrm{iv}} V_{\mathrm{er}(n)},
$$

where $K_{\mathrm{pv}}$ and $K_{\mathrm{iv}}$ are the proportional and integral gain constants of the voltage proportional integral (PI) controller, respectively, and the $V_{\text {tref }}$ value is taken as $700 \mathrm{~V}$. The $V_{\text {dcref }}$ value is taken as $600 \mathrm{~V}$ and the Zeigler-Nichols step response technique is implemented to calculate the associated 


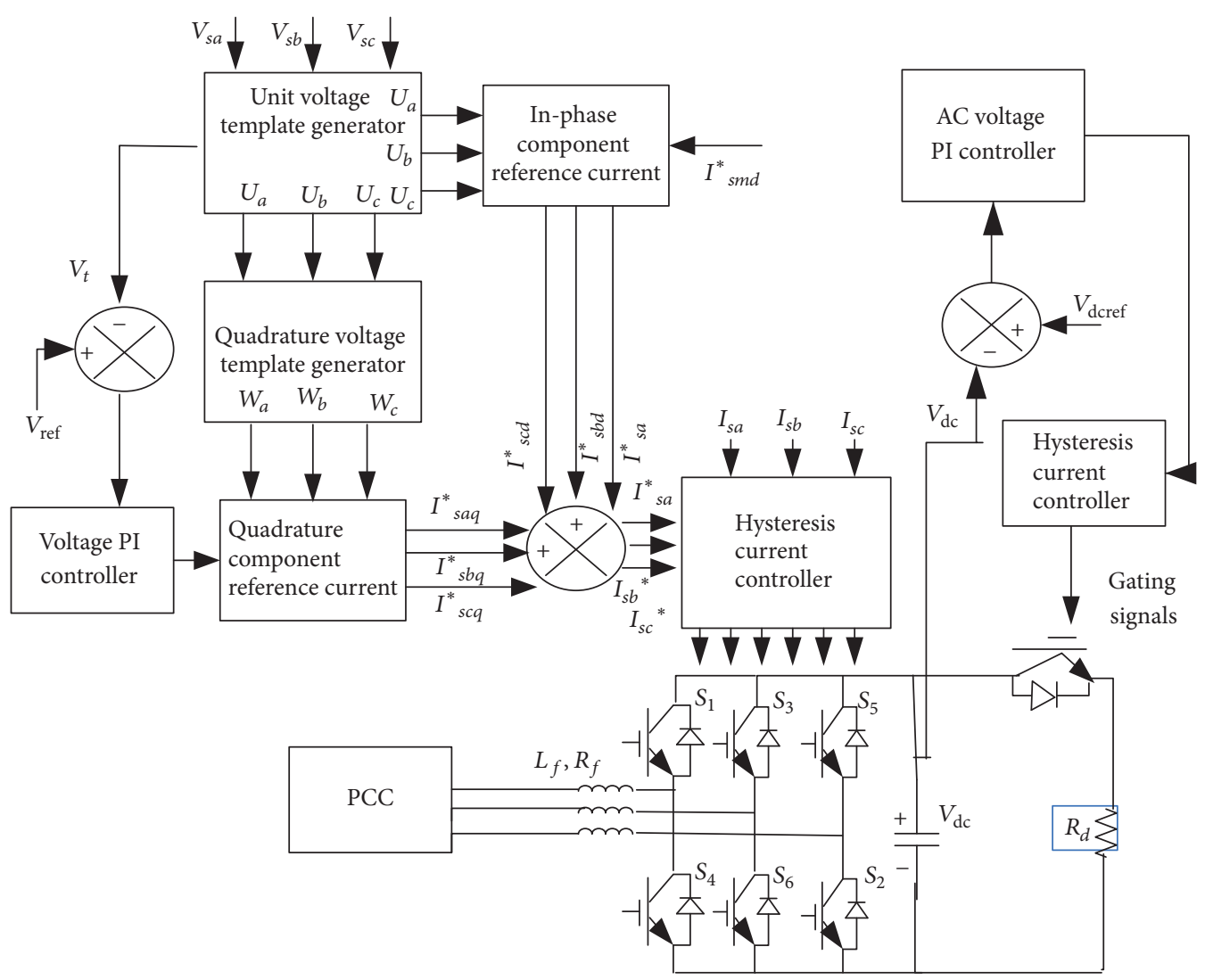

FIGURE 2: Basic control scheme with proportional integral controller for electronic load controller for SEIG system [9].

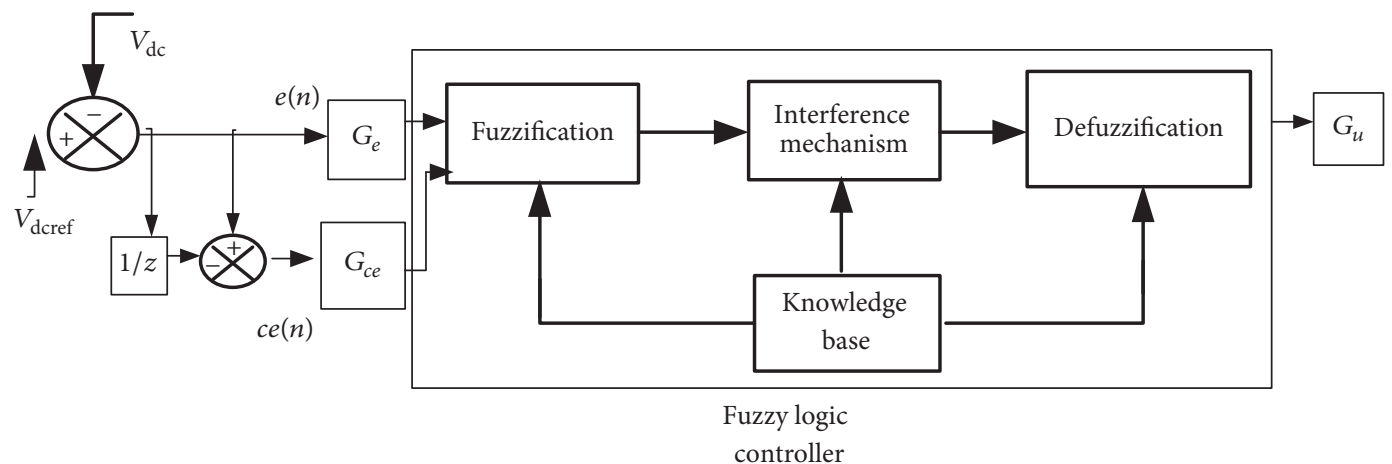

Figure 3: Detailed structure of fuzzy logic controller.

proportional gains $K_{\mathrm{pc}}$ and $K_{\mathrm{ic}}$ [4]. The step response of the open loop system is taken into account and from this response the maximum gradient $(G)$ and the point at which this line of maximum gradient intersects the time axis $(T)$ are calculated. The applied magnitude of the step response is " $U$ "; the gains of the PI controller are computed using the following equations:

$$
\begin{aligned}
& K_{\mathrm{pc}}=\bmod \left(\left\{\frac{1.2 U}{G T}\right\}\right), \\
& K_{\mathrm{ic}}=\bmod \left\{\frac{0.6 U}{\left(G T^{2}\right)}\right\} .
\end{aligned}
$$

The value of the above gains associated with the voltage open loop system is calculated and given in Appendix [9].

3.2. Fuzzy Logic Control. Fuzzy logic, unlike the Boolean logic, deals with problems that have uncertainty or vagueness and utilises membership functions with values varying between 0 and 1 . In fuzzy set theory concept, transition is between membership and nonmembership functions [12].

FLC consists of four basic components which are fuzzification, knowledge base, interference mechanism, and defuzzification. The detailed structure of FLC is shown in Figure 3. 


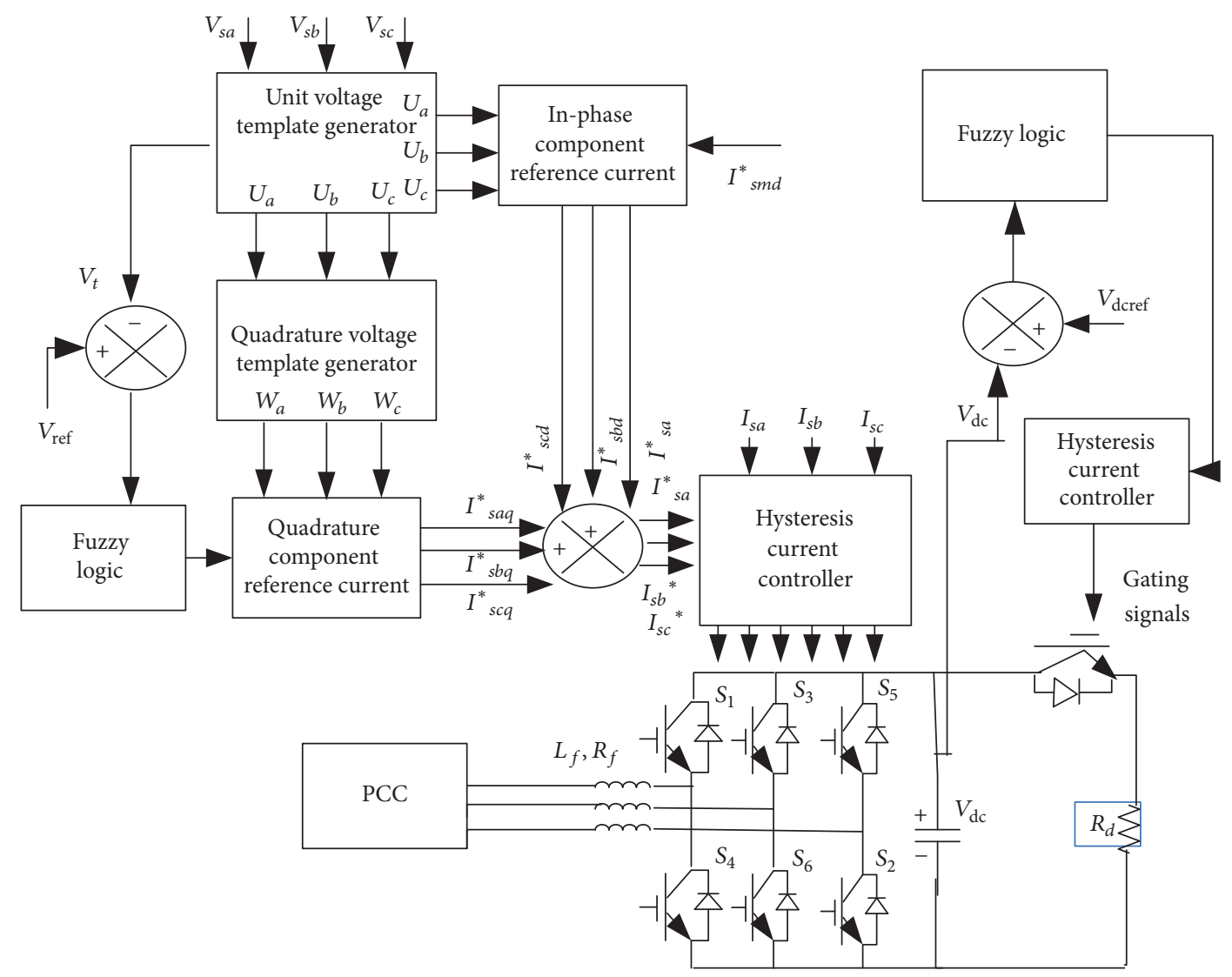

FIGURE 4: Schematic diagram of control scheme with fuzzy logic for electronic load controller for SEIG.

The DC voltage error $(e)$ and change in error $(c e)$ are the crisp inputs of the FLC. The fuzzification component converts these input signals into fuzzy values with the help of membership functions in the forms expressed by the fuzzy linguistic variables. It may be viewed as fuzzy sets. The knowledge base contains the data of linguistic descriptions which are expressed in terms of logical implications. The interference mechanism evaluates fuzzy information and applies set of control rules to convert the input signals into the fuzzified output. The defuzzification then uses methods such as centre of gravity and maximum and weighted mean and so forth and converts the input conditions into control signals. It is then applied to the actual system. The input signals are then expressed in fuzzy set notations using linguistic labels as characterised by membership grades before being processed by the fuzzy logic controller.

In this fuzzy controller design, triangular membership function is chosen due to its simplicity and ease of implementation and its symmetrical characteristic along the axis. The scaling factors $G_{e}, G_{c e}$, and $G_{u}$ are used in scaling the input and outputs as per the design of FLC [13]. The error " $e$ " and change of error " $c e$ " at the $n$th sampling instant which are used commonly as the inputs of FLC can be written as

$$
\begin{gathered}
e=V_{\mathrm{dcref}}-V_{\mathrm{dc}}, \\
c e(n)=e(n)-e(n-1) .
\end{gathered}
$$

TABLE 1: Rule base for fuzzy logic controller.

\begin{tabular}{llllcccc}
\hline$e(n)$ & & & \multicolumn{7}{c}{$c e(n)$} \\
& NB & NM & NS & ZE & PS & PM & PM \\
\hline NB & NB & NB & NB & NB & NM & NS & ZE \\
NM & NB & NB & NB & NM & NS & ZE & PS \\
NS & NB & NB & MN & NS & ZE & PS & PM \\
ZE & NB & NM & NS & ZE & PS & PM & PB \\
PS & NM & NS & ZE & PS & PM & PB & PB \\
PM & NS & ZE & PS & PM & PB & PB & PB \\
PB & ZE & PS & PM & PB & PB & PB & PB \\
\hline
\end{tabular}

The set of rules followed by the fuzzy logic controller is summarised in Table 1. In this paper, Mamdani's max-min inference scheme is applied to get an implied fuzzy set of tuning rules. Finally, centroid method is used to defuzzify the implied control signals [14-16]. Figure 4 explains the control scheme with FLC for ELC.

\section{Control Algorithm}

The working equations for control of the DC chopper circuit of the ELC and its components are given as follows. 


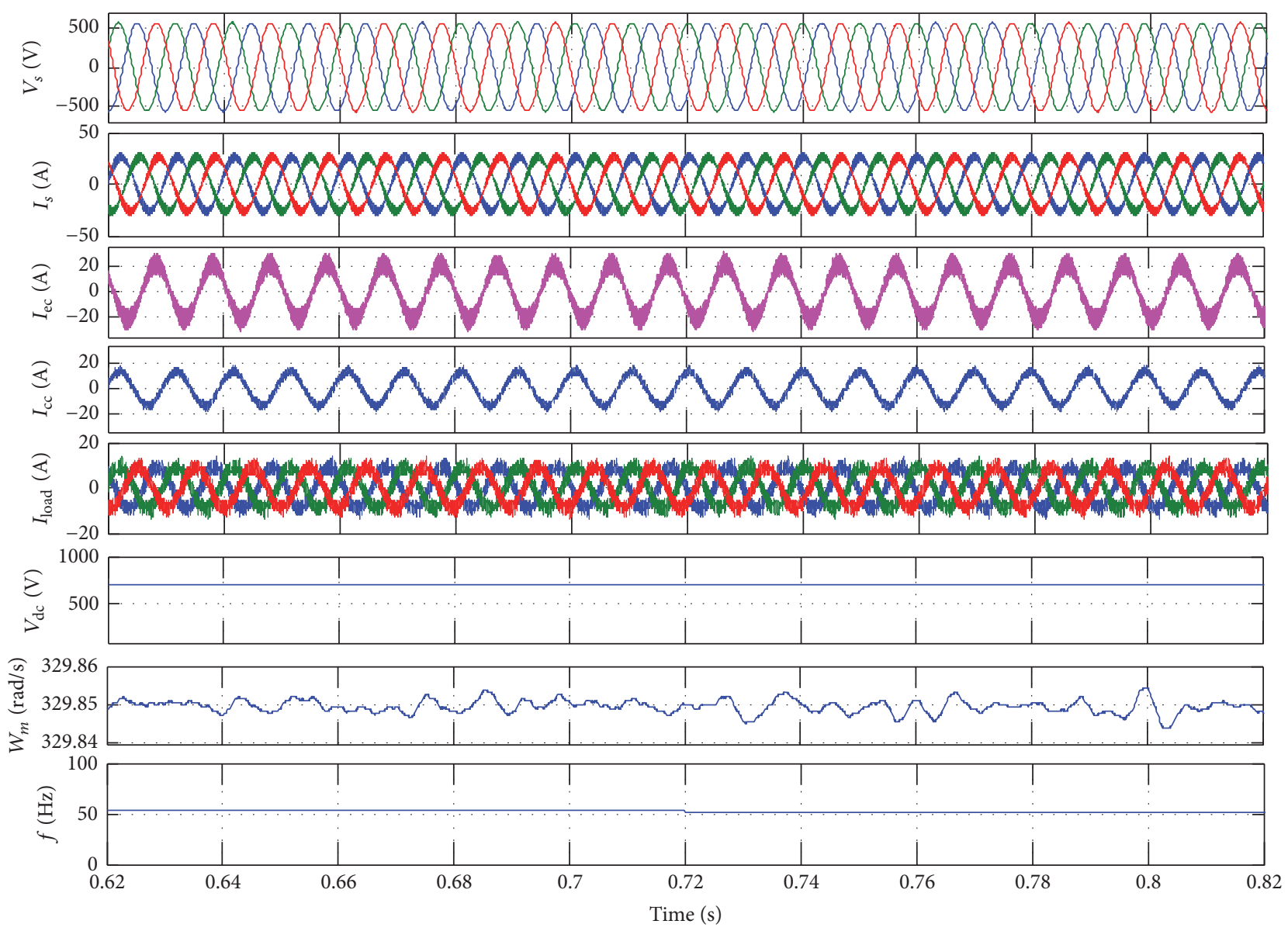

FIGURE 5: Performance of SEIG with fuzzy logic control based ELC connected to linear load [9].

4.1. DC Link Voltage. The DC link voltage is selected from the following equation:

$$
V_{\mathrm{dc}}>\frac{2 \sqrt{ } 2(V / \sqrt{ } 3)}{\mathrm{mi}}
$$

where modulation index ( $\mathrm{mi}$ ) is taken as 1 . For this calculated value of $677 \mathrm{~V}$, the nearby round off value of $V_{\mathrm{dc}}$ is computed as $700 \mathrm{~V}$.

4.2. DC Link Capacitor. The rms of AC input voltage and mean value of DC output voltage determine the rating of the uncontrolled rectifier and the IGBT based chopper switch. A constant DC voltage to the chopper switch is provided by a DC link capacitor that reduces the ripple content in the output voltage of a rectifier. Disturbance in the waveform may damage the functioning of the switch. The capacitor acts as a dead short circuit for a small period of time when there is a sudden switching of the controller. As a result, there is a chance for the bridge rectifier to get damaged. Hence, a trade-off value of $4000 \mu \mathrm{F}$ is chosen to reduce its charging current during the initial conditions and also reduce the ripple content of the DC voltage to a considerable value [11].
4.3. Dump Resistance $R_{d}$. Rating of $R_{d}$ can be calculated as

$$
R_{d}=\frac{\left(V_{\mathrm{dc}}\right)^{2}}{P(W)} \text {. }
$$

Thus, by keeping values of $V_{\mathrm{dc}}=700 \mathrm{~V}$ and rated power of $7500 \mathrm{~W}$, we obtain $R_{d}$ as $65 \Omega$. But the approachable value of $R_{d}$ for this control scheme is selected as $55 \Omega$ [9].

\section{Results and Discussion}

The waveforms of generator voltage $\left(V_{s}\right)$, generator current $\left(I_{s}\right)$, excitation current $\left(I_{\mathrm{ec}}\right)$, compensating current $\left(I_{\mathrm{cc}}\right)$, load current $\left(I_{\text {load }}\right)$, DC link voltage $\left(V_{\mathrm{dc}}\right)$, and rotor speed and frequency $\left(\omega_{m}, f\right)$ are shown in Figures 5-8. Also the graph of DC link voltage $\left(V_{\mathrm{dc}}\right)$ for both fuzzy logic controller and PI controller under linear and nonlinear load conditions is analyzed for their comparison. For the simulation, a $7.5 \mathrm{~kW}$, $415 \mathrm{~V}, 14.8 \mathrm{~A}, 4$-pole induction machine has been used as an induction generator and its parameters are stated in Appendix.

5.1. Performance of SEIG-ELC Using Fuzzy Controller Connected to Linear and Nonlinear Load. Figure 5 shows the performance of the ELC based on fuzzy logic controller 

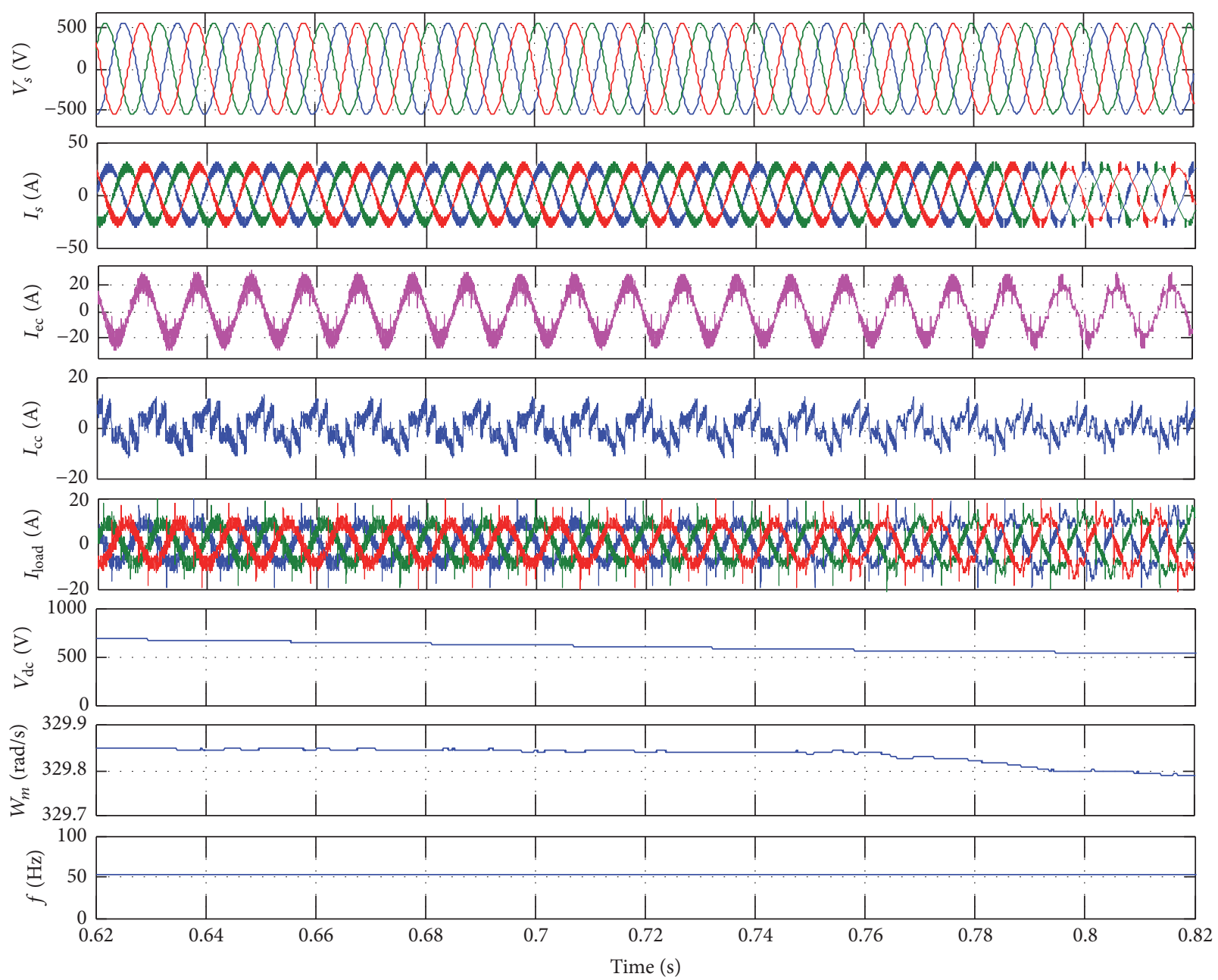

FIGURE 6: Performance of SEIG with fuzzy logic control based ELC connected to nonlinear load [9].

system connected to a balanced reactive load. At $0.62 \mathrm{sec}$, $7.5 \mathrm{~kW}$ balanced reactive load of $0.8 \mathrm{PF}$ is applied to the system. As we can observe the generator voltage remains stable after the application of load. For nonlinear load conditions, Figure 6 shows the performance of the SEIG system with $6 \mathrm{~kW}$ resistive load connected at the DC end of threephase uncontrolled rectifier. At $0.62 \mathrm{sec}$, the nonlinear load is connected and is maintained till the end. The stable level of $V_{\mathrm{dc}}$ is slightly decreased for few seconds but gains a stable level later and is maintained till the end of the simulation.

\subsection{Performance of SEIG-ELC Using PI Controller System} Connected to 3-Phase Linear and Nonlinear Load. Figure 7 shows the performance of the SEIG-ELC system based on PI voltage control when connected to linear reactive load. At $0.62 \mathrm{sec}$. a balanced reactive load of $7.5 \mathrm{~kW}$ of $0.8 \mathrm{PF}$ lagging is connected and the voltage remains stable all throughout the system. Figure 8 analyzes the performance of this system under nonlinear load which consists of a three-phase uncontrolled rectifier circuit with a resistive load of $7.5 \mathrm{~W}$ at its DC end. At $0.62 \mathrm{sec}$, nonlinear load is applied on the system and it is observed that the voltage and frequency remain stable all throughout the simulation with power quality.

5.3. Comparative Analysis of DC Link Voltage in SEIG-ELC System. Figure 9 shows the comparison of DC link voltage in fuzzy logic control and PI voltage control based SEIGELC system under linear load. The settling time taken by the fuzzy control is less as compared to the PI control scheme. At $0.62 \mathrm{sec}$, when the linear reactive load is applied to both the systems, the time taken by the DC link voltage in fuzzy control is less and also achieves a higher stable voltage than the PI control. The DC link voltage of the PI control system reaches a stable level at nearly $0.85 \mathrm{sec}$. Thus, the settling time of fuzzy logic controller is less than the classic proportional integral controller. Similarly, Figure 10 shows the comparison of both control systems under nonlinear load condition. At $0.62 \mathrm{sec}$, when the nonlinear load is connected, the DC link voltage associated with fuzzy control settles at nearly $0.7 \mathrm{sec}$ which is lesser than the settling time of $0.8 \mathrm{sec}$ in PI control. Thus, the results portray that the fuzzy logic controller based 

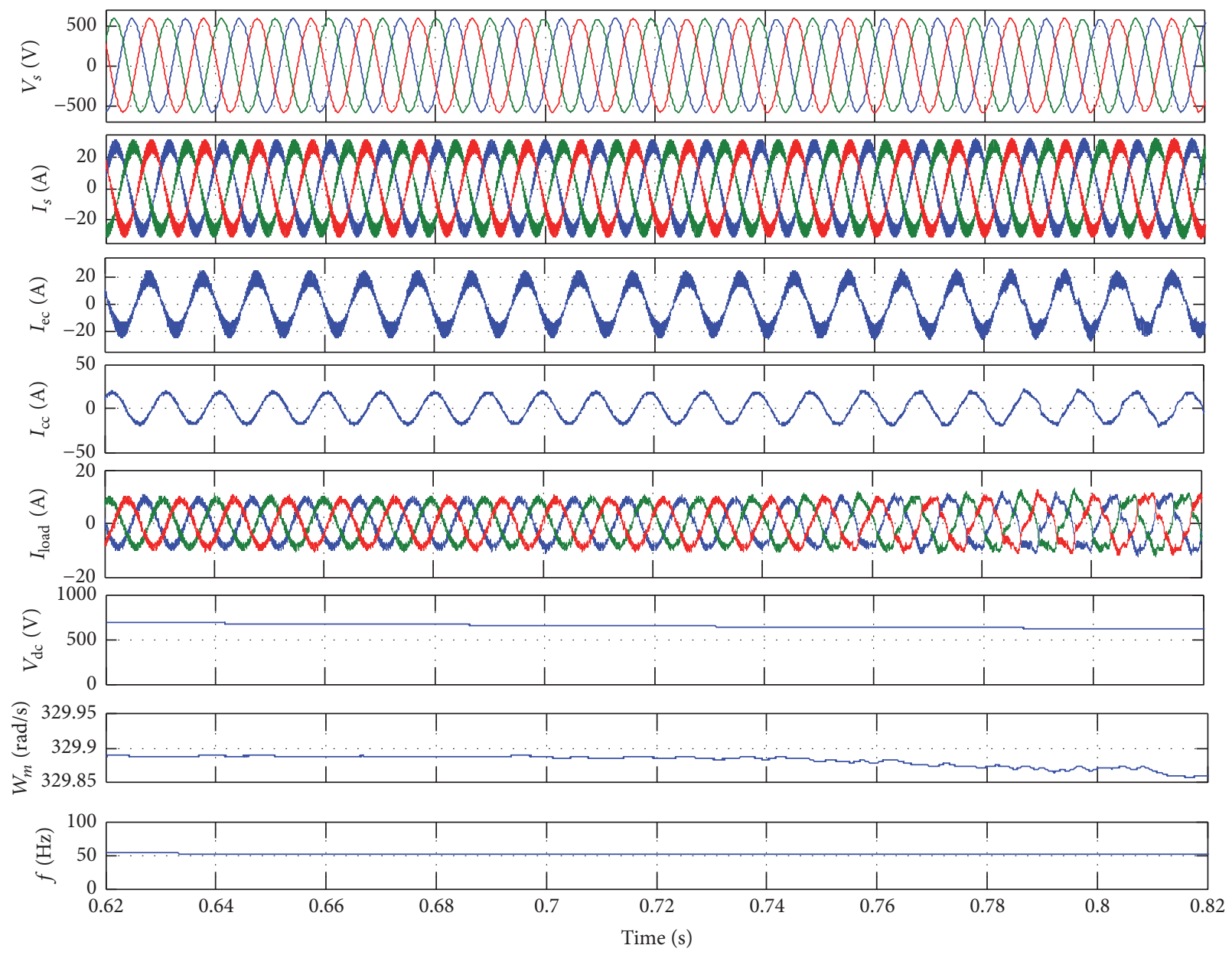

FIGURE 7: Performance of SEIG with proportional integral control based ELC connected to linear load.

ELC system is superior as a voltage controller than the PI control based ELC system for constant power SEIG system.

\section{Conclusions}

An efficient control scheme based on fuzzy logic control for a constant power driven SEIG is presented in this paper. It is then compared with the traditional PI controller based SEIG-ELC system. The comparative analysis on the basis of the settling time of the DC link voltage portrays that the fuzzy logic based ELC is superior than the proportional integral based ELC. The voltage and frequency variations are proportional to reactive and active power, respectively. Thus, the ELC with the help of proper switching signals maintains active and reactive power balance. $V_{s}$ and $f$, that is, the generator voltage and the frequency, respectively, remain constant throughout and do not decay on application of load. This depicts that the proposed fuzzy logic based ELC performs voltage and frequency regulation under both linear and nonlinear load conditions. To further examine the robustness of the proposed scheme, the above configuration can be analyzed with modern variable frequency drives
(VFDs) and industrial loads. The system can be implemented in microgrid and can be connected with other isolated generating systems or grids.

\section{Appendix}

\section{A. Data of SEIG}

The parameters of $7.5 \mathrm{~kW}, 415 \mathrm{~V}, 50 \mathrm{~Hz}$, Y-connected, 4-pole induction machine are given below:

$R_{s}=1 \Omega, R_{r}=0.77 \Omega, X_{l r}=X_{l s}=1.5 \Omega, J=$ $0.1384 \mathrm{~kg}-\mathrm{m}^{2}$, and $L m=0.068 \mathrm{H}$.

\section{B. Controller Parameters}

$L_{f}=1.2 \mathrm{mH} ; R_{f}=0.06 \Omega$ and $C_{\mathrm{dc}}=4000 \mu \mathrm{F} ; R_{d}=55 \Omega$.

For AC PI voltage controller, $K_{\mathrm{pv}}=0.16$ and $K_{\mathrm{iv}}=$ 0.14 .

For DC link capacitor voltage PI controller, $K_{\mathrm{pc}}=$ 1.98 and $K_{\text {ic }}=0.001$. 

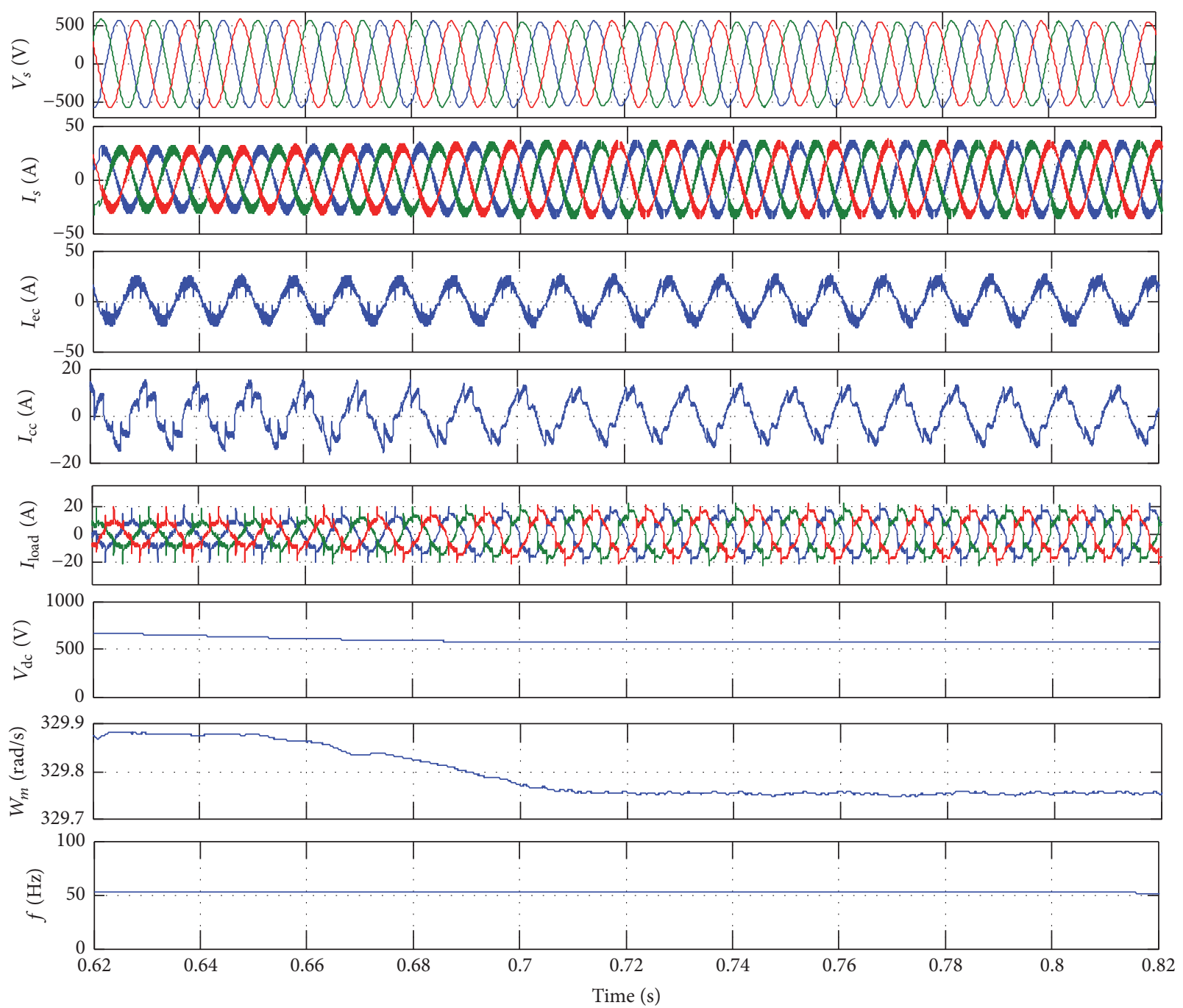

FIGURE 8: Performance of SEIG with proportional integral control based ELC connected to nonlinear load.

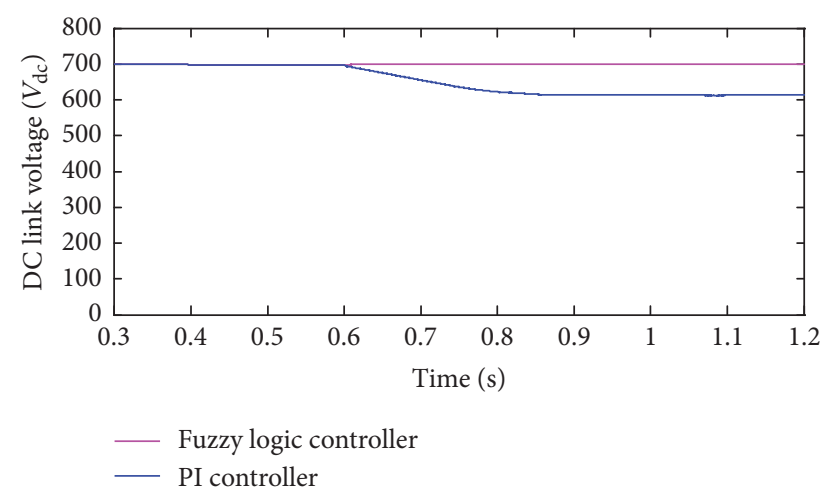

FIGURE 9: Comparison of DC link voltage for fuzzy logic control and PI control based ELC for SEIG system supplying linear load.

\section{Consumer Loads}

Reactive Load. It is $7.5 \mathrm{~kW}, 0.8 \mathrm{PF}$ lagging three-phase load.

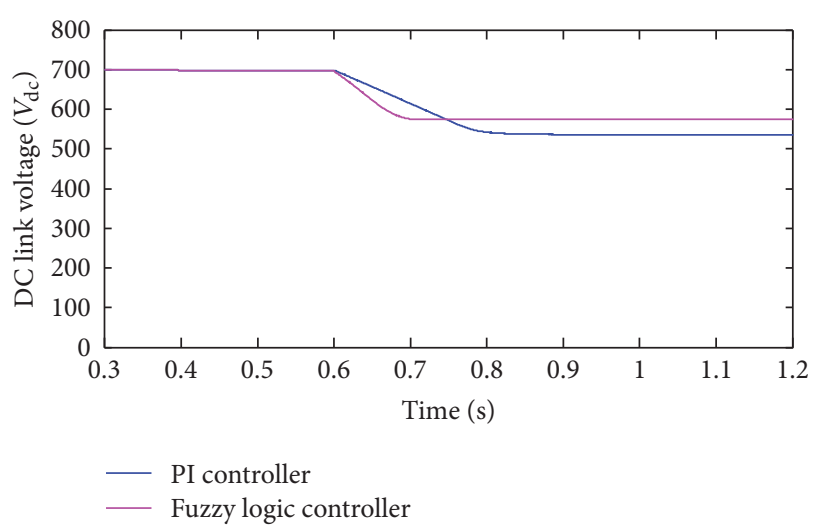

Figure 10: Comparison of DC link voltage for fuzzy logic control and PI control based ELC for SEIG system supplying nonlinear load.

Nonlinear Load. It is $6 \mathrm{~kW}$ at DC end of three-phase diode rectifier. 


\section{Prime Mover Characteristics}

$$
\begin{aligned}
& T_{\text {sh }}=K_{1}-K_{2} \omega_{r} . \\
& K_{1}=3300, K_{2}=100 .
\end{aligned}
$$

\section{Conflicts of Interest}

The authors declare that there are no conflicts of interest regarding the publication of this paper.

\section{References}

[1] R. C. Bansal, "Three-phase self-excited induction generators: an overview," IEEE Transactions on Energy Conversion, vol. 20, no. 2, pp. 292-299, 2005.

[2] M. Dandan, "Self-excited induction generator - a study based on nonlinear dynamic methods," in School of Electrical and Electronics, NewCastle University, UK, May 2012.

[3] B. Singh, S. S. Murthy, and S. Gupta, "STATCOM-based voltage regulator for self-excited induction generator feeding nonlinear loads," IEEE Transactions on Industrial Electronics, vol. 53, no. 5, pp. 1437-1452, 2006.

[4] B. Singh and G. K. Kasal, "Solid state voltage and frequency controller for a stand alone wind power generating system," IEEE Transactions on Power Electronics, vol. 23, no. 3, pp. 11701177, 2008.

[5] B. Singh and G. K. Kasal, "Voltage and frequency controller for isolated asynchronous generators feeding 3-phase 4-wire loads," in Proceedings of the 2006 IEEE International Conference on Industrial Technology, ICIT, pp. 2773-2778, ind, December 2006.

[6] B. Singh and G. K. Kasal, "Solid state controller for an isolated wind energy conversion system feeding dynamic loads," in Proceedings of the 8th International Power Engineering Conference, IPEC 2007, pp. 532-537, Singapore, December 2007.

[7] B. Singh, G. K. Kasal, A. Chandra, and K.-A. Haddad, "Electronic load controller for a parallel operated isolated asynchronous generator feeding various loads," Journal of Electromagnetics Analysis and Applications, vol. 3, no. 4, pp. 101-114, 2011.

[8] A. Banerji, S. K. Biswas, and B. Singh, "Voltage and frequency controller for an autonomous asynchronous generator," International Journal on Electrical Engineering and Informatics, vol. 6, no. 2, pp. 250-265, 2014.

[9] E. Mishra and S. Tiwari, "Proportional Integral based Electronic load controller for Self excited induction generator," International Journal of Innovative Engineering Research, vol. 6, no. 2, 2016.

[10] B. Singh, K. Al-Haddad, and A. Chandra, "Harmonic elimination, reactive power compensation and load balancing in threephase, four-wire electric distribution systems supplying nonlinear loads," Electric Power Systems Research, vol. 44, no. 2, pp. 93-100, 1998.

[11] Y. K. Chauhan, S. K. Jain, and B. Singh, "A prospective on voltage regulation of self-excited induction generators for industry applications," IEEE Transactions on Industry Applications, vol. 46, no. 2, pp. 720-730, 2010.

[12] P. Karuppanan and K. Mahapatra, "PLL with fuzzy logic controller based shunt active power filter for harmonic and reactive power compensation," in Proceedings of the India International
Conference on Power Electronics, IICPE 2010, India, January 2011.

[13] C. Kathirvel and K. Porkumaran, "Fuzzy Logic based voltage and frequency of a self excited induction generator for micro hydro turbines for rural applications," Journal of Theoretical and Applied Information Technology, vol. 54, no. 1, pp. 1-7, 2013.

[14] Y. Sofian and M. Iyas, "Design of electronic load controller for a self excited induction generator using fuzzy logic method based microcontroller," in Proceedings of the 2011 International Conference on Electrical Engineering and Informatics, ICEEI 2011, India, July 2011.

[15] S. Gao, S. S. Murthy, G. Bhuvaneswari, and M. S. L. Gayathri, "Design of a microcontroller based electronic load controller for a self excited induction generator supplying single-phase loads," Journal of Power Electronics, vol. 10, no. 4, pp. 444-449, 2010.

[16] N. Gupta, S. P. Singh, and S. P. Dubey, "Fuzzy logic controlled shunt active power filter for reactive power compensation and harmonic elimination," in Proceedings of the 2011 2nd International Conference on Computer and Communication Technology, ICCCT-2011, pp. 82-87, India, September 2011. 


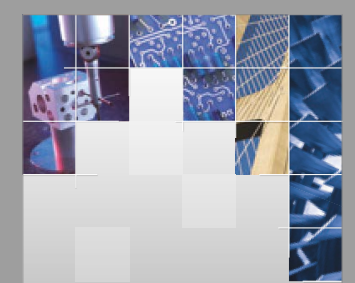

\section{Enfincering}
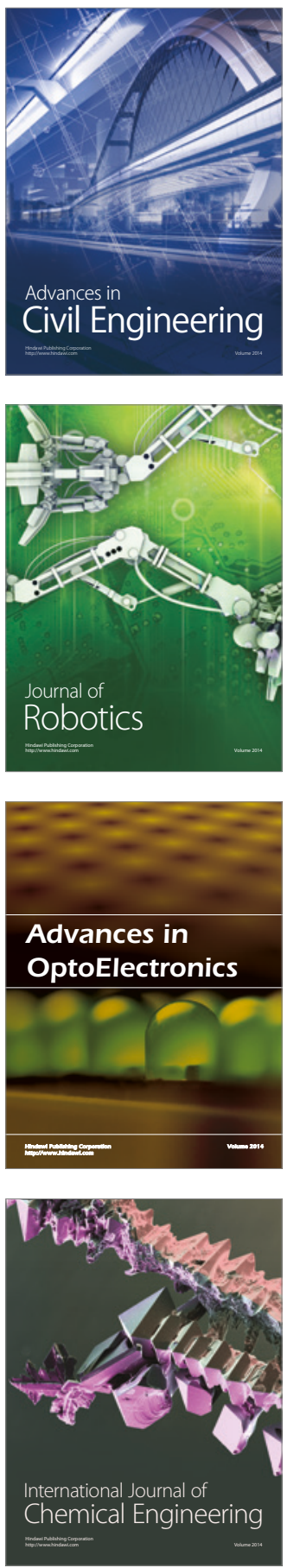

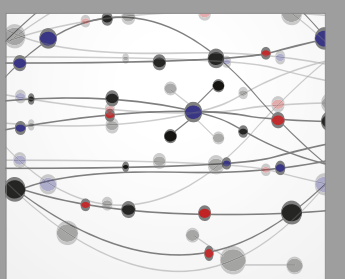

The Scientific World Journal

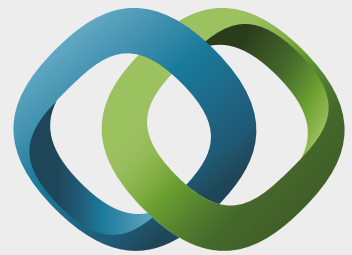

\section{Hindawi}

Submit your manuscripts at

https://www.hindawi.com
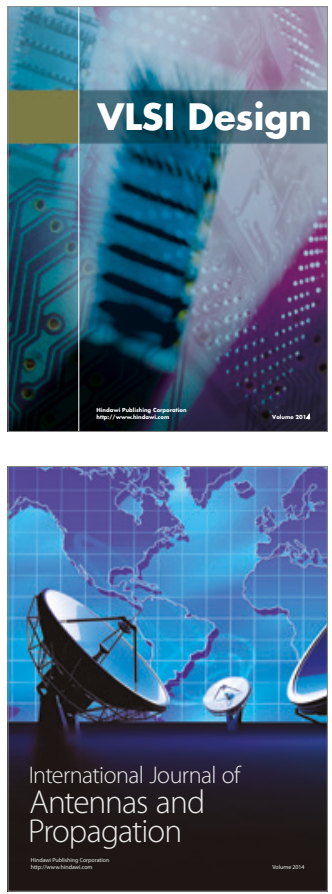

\section{Rotating}

Machinery
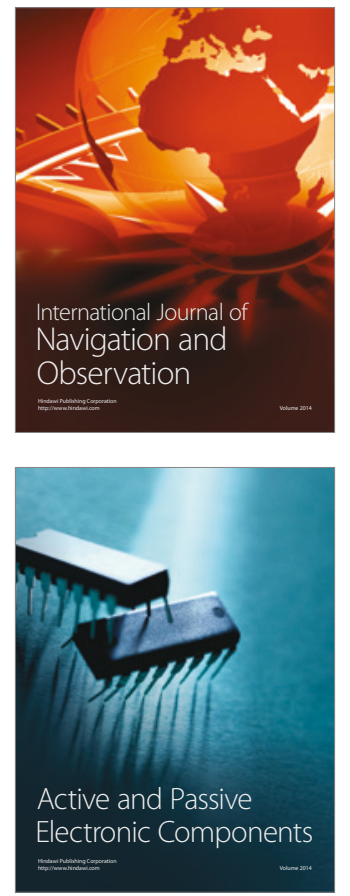
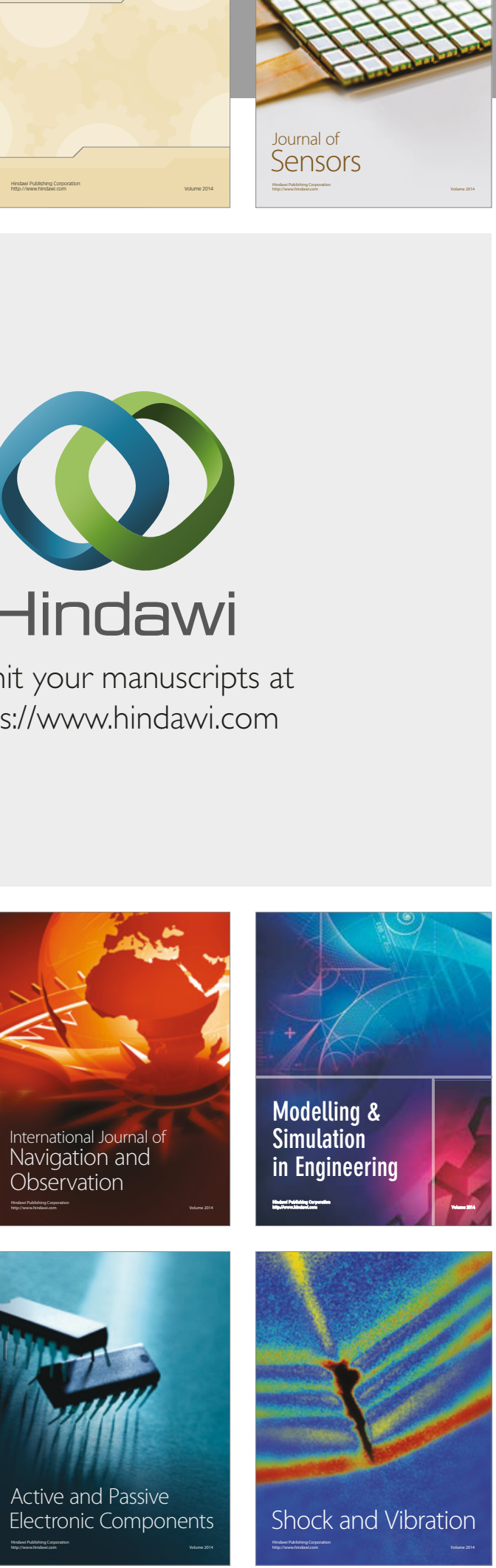
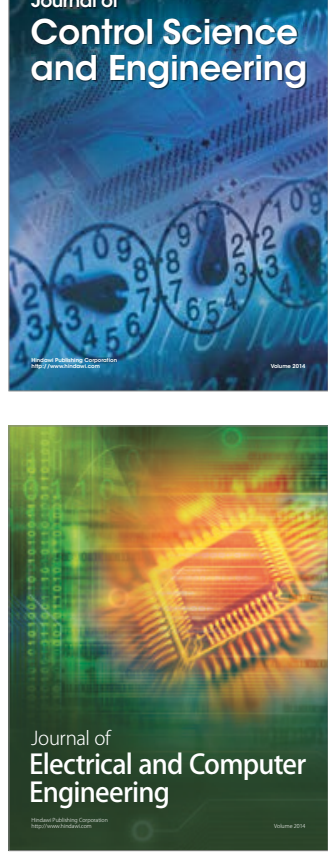

Distributed

Journal of

Control Science

and Engineering
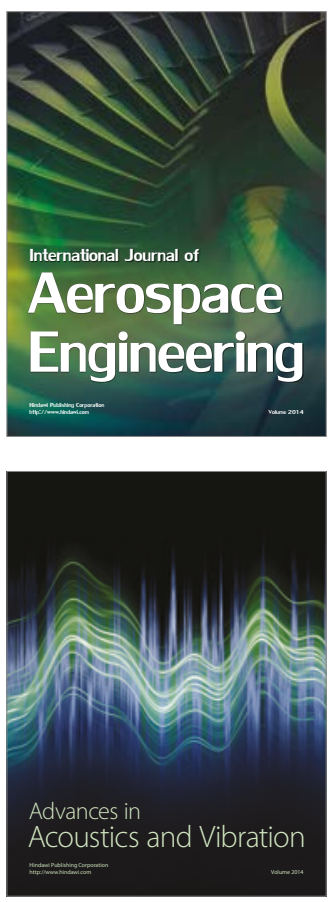

Sensor Networks 